Supporting Information

\title{
Deracemization of Chiral-at-Ruthenium Catalyst by Diastereoselective Dynamic Resolution
}

Dominik Baran, Sergei I. Ivlev, Eric Meggers*

Fachbereich Chemie, Philipps-Universität Marburg, Hans-Meerwein-Strasse 4, 35043 Marburg, Germany

*Corresponding author: meggers@ chemie.uni-marburg.de

\section{Table of Contents}

1. Determination of Enantiomeric Ratios of Non-Racemic Ruthenium Complexes ....................S2

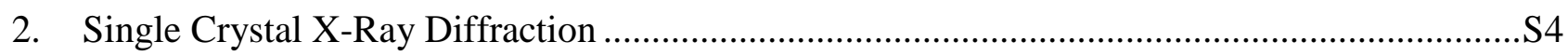

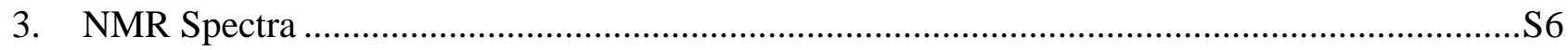

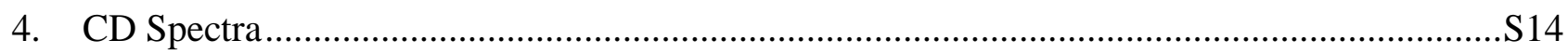

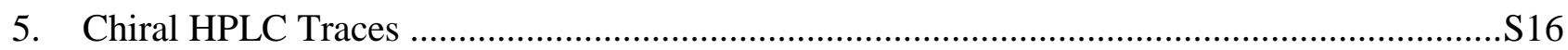

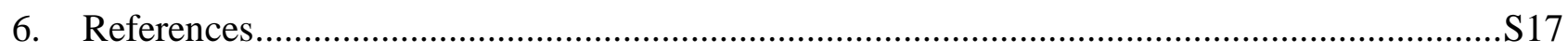




\section{Determination of Enantiomeric Ratios of Non-Racemic Ruthenium Complexes}

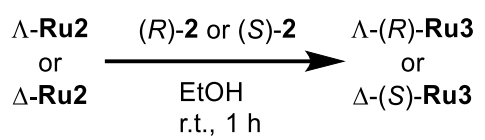

Scheme S1. Reaction of $\Lambda$ - or $\Delta$-Ru2 with $(R)$ - or $(S)$-4-phenyl-4,5-dihydrooxazole (2).

Method: Coordination of the enantiomerically pure chiral ligand $(R)-$ or $(S)-\mathbf{2}$ to $\Lambda$ - or $\Delta$ - $\mathbf{R u} 2$ was used to convert it to the corresponding auxiliary complexes $\Lambda-(R)-\mathbf{R u 3}$ or $\Delta-(S)-\mathbf{R u 3}$. Determination of the diastereomeric ratio by ${ }^{1} \mathrm{H}$ NMR analysis was used as a measurement for the enantiomeric purity of $\Lambda$ - and $\Delta-\mathbf{R u} 2$ (Scheme S1).

Procedure: Purified samples of $\Lambda$ - or $\Delta$-Ru2 $(4.2 \mathrm{mg}, 0.005 \mathrm{mmol})$ and the auxiliary ligand $(R)$ - or (S)-2 (0.8 mg, $0.005 \mathrm{mmol}, 1.05$ equiv) were stirred in $\mathrm{EtOH}(0.25 \mathrm{~mL})$ for $1 \mathrm{~h}$ at room temperature. The resulting solid-liquid mixture was evaporated to dryness, the residue dissolved in acetone- $d_{6}$ and analyzed by ${ }^{1} \mathrm{H}$ NMR. 
c)

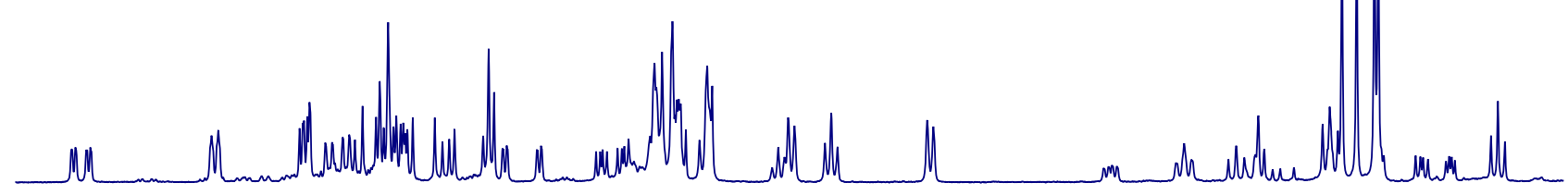

b)

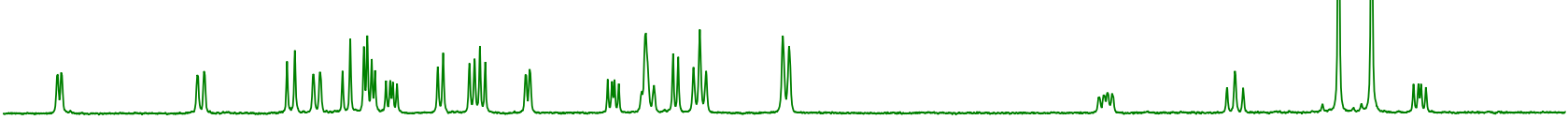

a)

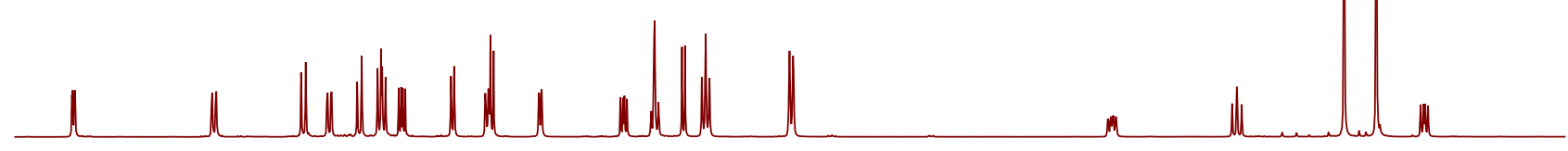

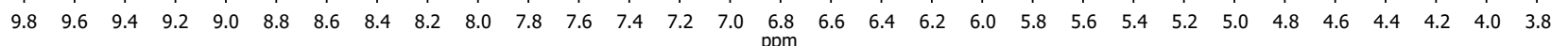

Figure S1. Excerpts of ${ }^{1} \mathrm{H}$ NMR spectra (acetone- $\left.d_{6}\right)$. a) Complex $\Delta-(S)$-Ru3. b) Reaction of $\Delta-\mathbf{R u} 2$

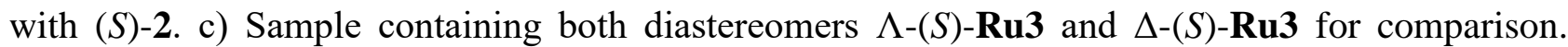
Identical results were obtained when $\Lambda$-Ru2 was used.

Results: No signals for the other diastereomers $\Lambda-(S)-\mathbf{R u 3}$ or $\Delta-(R)-\mathbf{R u} 3$ could be observed (Figure S1). Thus, we conclude an enantiomeric ratio for $\Lambda$ - and $\Delta-\mathbf{R u} 2>20: 1 \mathrm{er}$. 


\section{Single Crystal X-Ray Diffraction}

A suitable crystal of $\mathrm{C}_{27} \mathrm{H}_{20} \mathrm{ClN}_{4} \mathrm{ORu}\left(\mathrm{PF}_{6}\right)$ was selected under inert oil and mounted using a MiTeGen loop. Intensity data of the crystal were recorded with a D8 Quest diffractometer (Bruker AXS). The instrument was operated with Mo-K $\alpha$ radiation $(0.71073 \AA$, microfocus source $)$ and equipped with a PHOTON 100 detector. Evaluation, integration and reduction of the diffraction data was carried out using the Bruker APEX 3 software suite. ${ }^{\mathrm{s} 1}$ Multi-scan and numerical absorption corrections were applied using the SADABS program. ${ }^{\mathrm{s} 2, \mathrm{~s} 3}$ The structure was solved using dual-space methods (SHELXT-2014/5) and refined against $F^{2}$ (SHELXL-2018/3 using ShelXle interface). ${ }^{\text {s4-s6 }}$ The crystal structure was refined as an inversion twin. All non-hydrogen atoms were refined with anisotropic displacement parameters. The hydrogen atoms were refined using the "riding model" approach with isotropic displacement parameters 1.2 times (1.5 times for terminal methyl groups) of that of the preceding carbon atom. The structure contains channel-like solvent accessible voids. It was not possible to find any good model for the diffused electron density in the voids, therefore, it was eliminated using the SQUEEZE algorithm ${ }^{\mathrm{s} 7}$ in the PLATON software. ${ }^{\mathrm{s} 8}$ CCDC 2113800 contains the supplementary crystallographic data for this paper. These data can be obtained free of charge from The Cambridge Crystallographic Data Centre via www.ccdc.cam.ac.uk/structures.

Single crystals suitable for X-ray diffractions were obtained by preparation in an NMR tube. The complex (2 mg) was dissolved in small amount of $\mathrm{MeCN}(0.1-0.2 \mathrm{~mL})$ and carefully layered with $\mathrm{Et}_{2} \mathrm{O}$. The tube was left standing at room temperature until formation of singly crystals was observed. The data and details of $r a c-\mathbf{R u} 1$ are presented in Table S1. 
Table S1. Crystal data and details for structure determination.

\begin{tabular}{|c|c|}
\hline & $r a c-\mathbf{R u 1}$ \\
\hline Identification Code & DBMA00326 \\
\hline Empirical Formula & $\mathrm{C}_{27} \mathrm{H}_{20} \mathrm{ClF}_{6} \mathrm{~N}_{4} \mathrm{OPRu}$ \\
\hline Molar mass $\left(\mathrm{g} \mathrm{mol}^{-1}\right)$ & 697.96 \\
\hline \multirow{3}{*}{$a, b, c(\AA)$} & $16.8750(9)$ \\
\hline & $13.2722(8)$ \\
\hline & $13.4684(8)$ \\
\hline$\beta\left(^{\circ}\right)$ & $108.780(2)$ \\
\hline$V\left(\AA^{3}\right)$ & $2855.9(3)$ \\
\hline$Z$ & 4 \\
\hline$\rho_{\text {calc. }}\left(\mathrm{g} \mathrm{cm}^{-3}\right)$ & 1.623 \\
\hline$\mu(\mathrm{mm})$ & 0.766 \\
\hline Color & orange \\
\hline Crystal habitus & needle \\
\hline Crystal size $\left(\mathrm{mm}^{-1}\right)$ & $0.325 \times 0.106 \times 0.064$ \\
\hline$T(\mathrm{~K})$ & 100 \\
\hline$\lambda(\AA)$ & $0.71073\left(\mathrm{Mo}_{\mathrm{N}}-\mathrm{K}_{\alpha}\right)$ \\
\hline$\theta$ range $\left(^{\circ}\right)$ & 1.995 to 29.635 \\
\hline \multirow{3}{*}{ Range of Miller indices } & $-23 \leq h \leq 23$ \\
\hline & $-18 \leq k \leq 18$ \\
\hline & $-18 \leq l \leq 18$ \\
\hline Absorption correction & multi-scan and numerical \\
\hline$T_{\min }, T_{\max }$ & $0.8319,0.9897$ \\
\hline$R_{\text {int }}, R_{\sigma}$ & $0.0368,0.0302$ \\
\hline Completeness of the data set & 1.000 \\
\hline No. of measured reflections & 45444 \\
\hline No. of independent reflections & 8042 \\
\hline No. of parameters & 374 \\
\hline No. of restraints & 2 \\
\hline$S$ (all data) & 1.046 \\
\hline$R(F)(I \geq 2 \sigma(I)$, all data $)$ & $0.0258,0.0294$ \\
\hline$w R\left(F^{2}\right)(I \geq 2 \sigma(I)$, all data $)$ & $0.0538,0.0549$ \\
\hline Volume fraction of the $2^{\text {nd }}$ twin component & $0.23(2)$ \\
\hline$\Delta \rho_{\max }, \Delta \rho_{\min }\left(\mathrm{e} \AA^{-3}\right)^{*}$ & $0.465,-0.381$ \\
\hline
\end{tabular}

*The values of the residual Fourier electron density correspond to the last stage of refinement using a SQUEEZE-corrected dataset, see details in Supporting Information and in SQUEEZE-related part of the CIF file. 


\section{NMR Spectra}

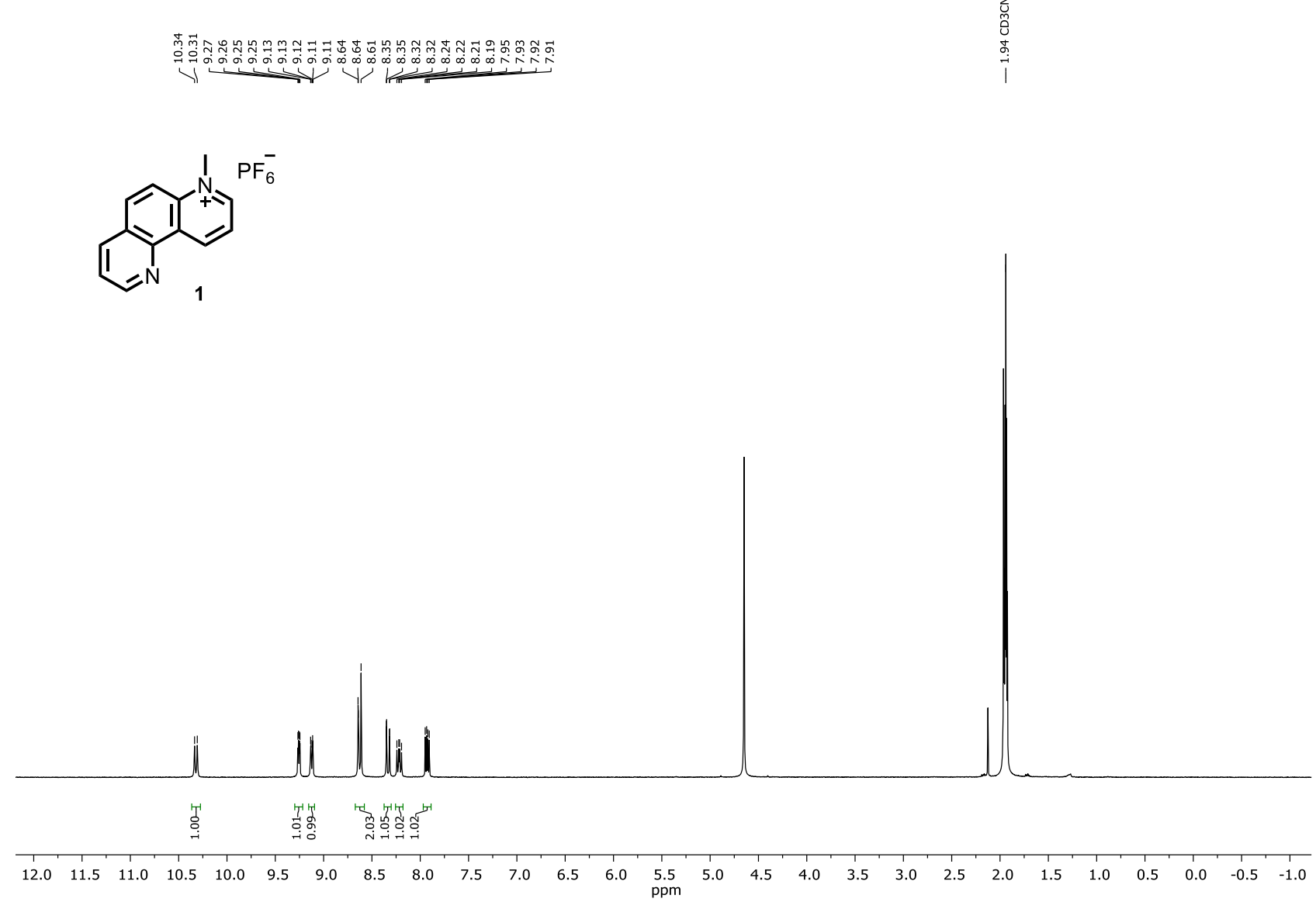

Figure S2. ${ }^{1} \mathrm{H}$ NMR (300 MHz) spectrum of 1 in $\mathrm{CD}_{3} \mathrm{CN}$.

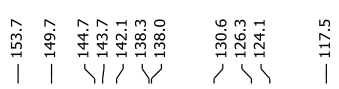

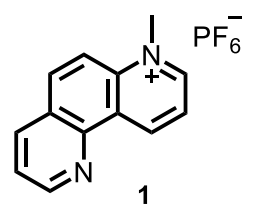



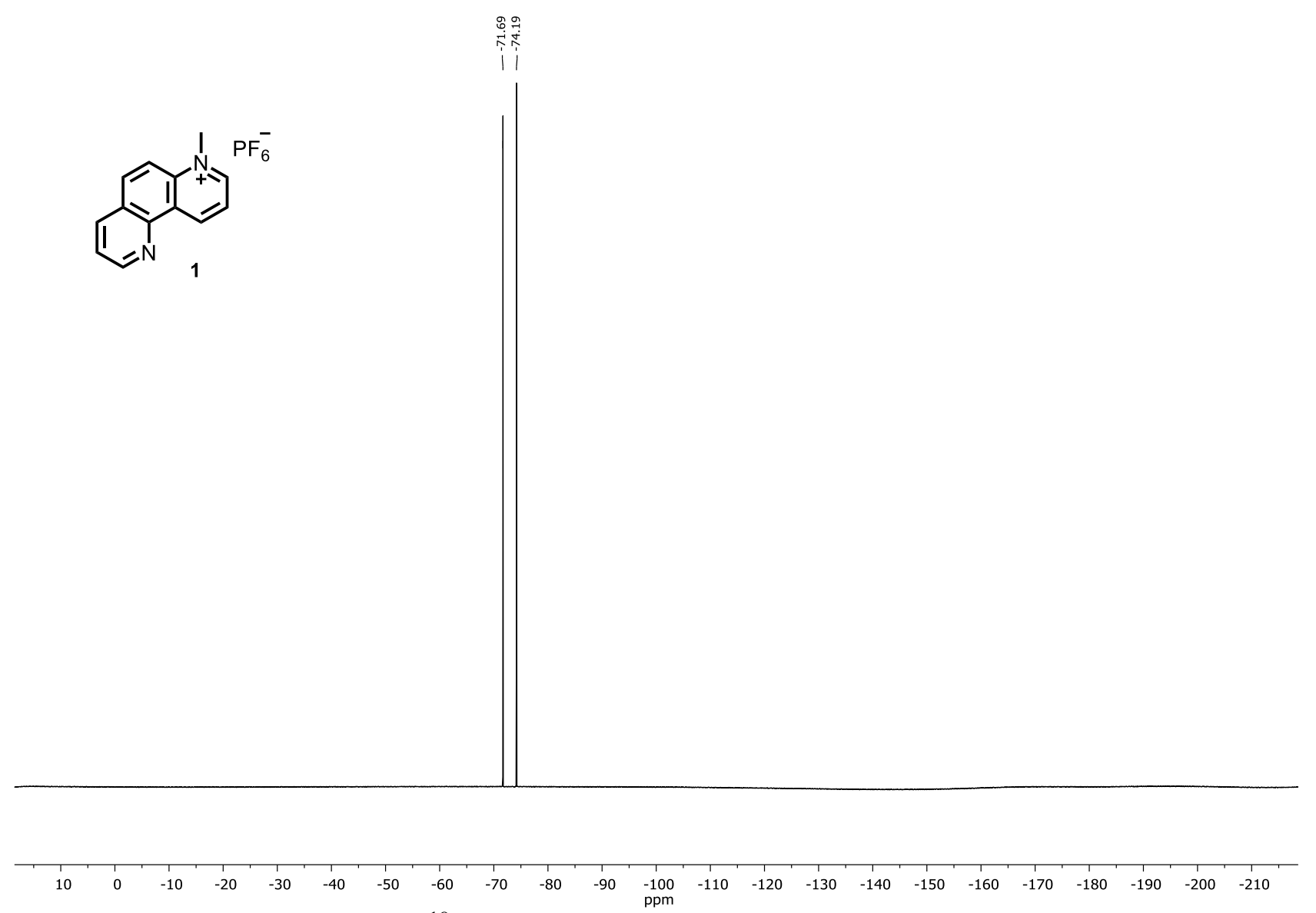

Figure S4. ${ }^{19} \mathrm{~F}$ NMR (282 MHz) spectrum of 1 in $\mathrm{CD}_{3} \mathrm{CN}$.
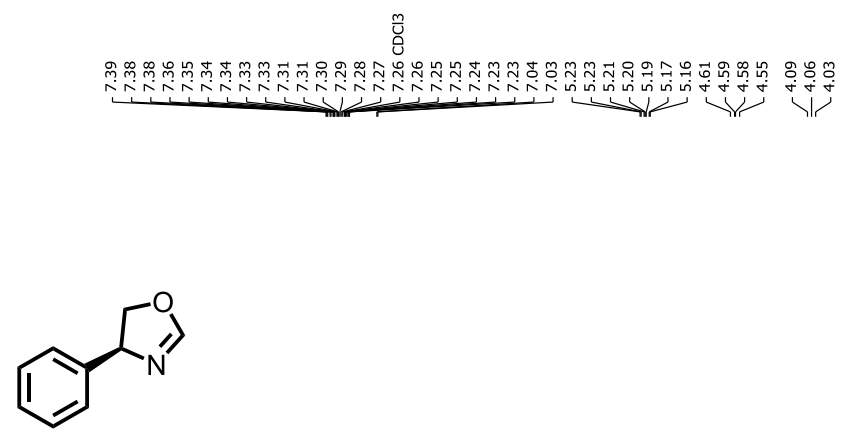

(S)-2

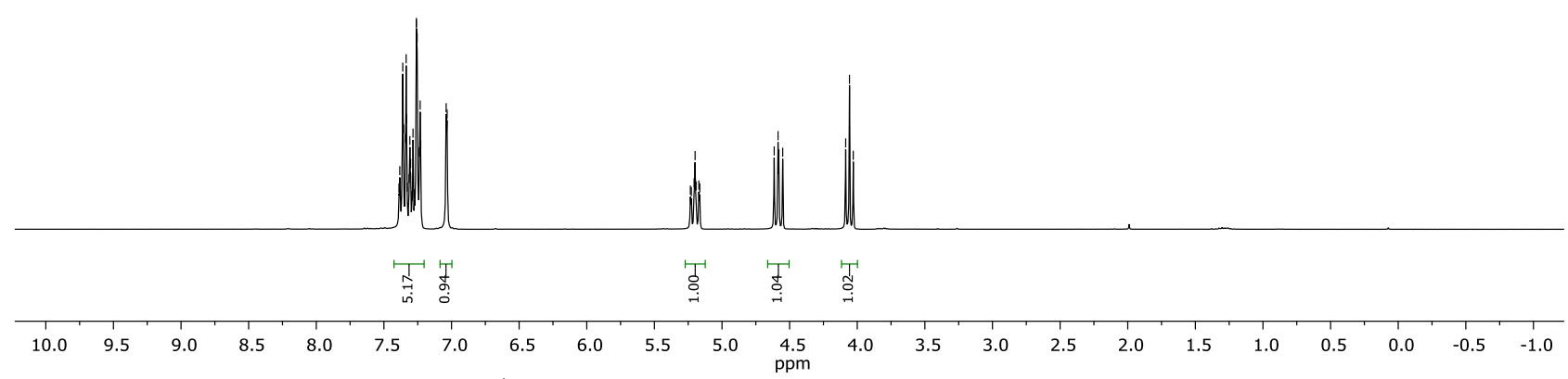

Figure S5. ${ }^{1} \mathrm{H}$ NMR $(300 \mathrm{MHz})$ spectrum of $(S)-2$ in $\mathrm{CDCl}_{3}$. 
<smiles>C1=NC(c2ccccc2)CO1</smiles>

(S)-2

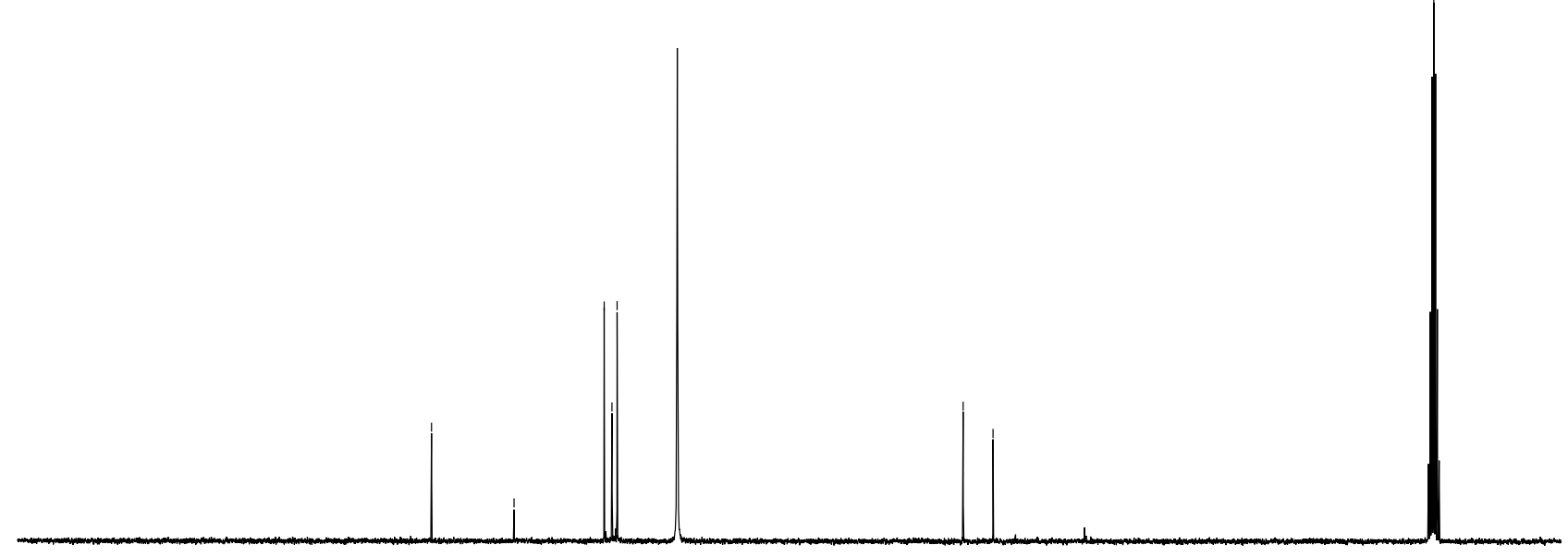

\begin{tabular}{llllllllllllllllllllllllllllll}
\hline 20 & 210 & 200 & 190 & 180 & 170 & 160 & 150 & 140 & 130 & 120 & 110 & 100 & 90 & 80 & 70 & 60 & 50 & 40 & 30 & 20 & 10 & 0 & -10
\end{tabular}

Figure S6. ${ }^{13} \mathrm{C}$ NMR $(75 \mathrm{MHz})$ of $(S)-2$ in $\mathrm{CD}_{3} \mathrm{CN}$.

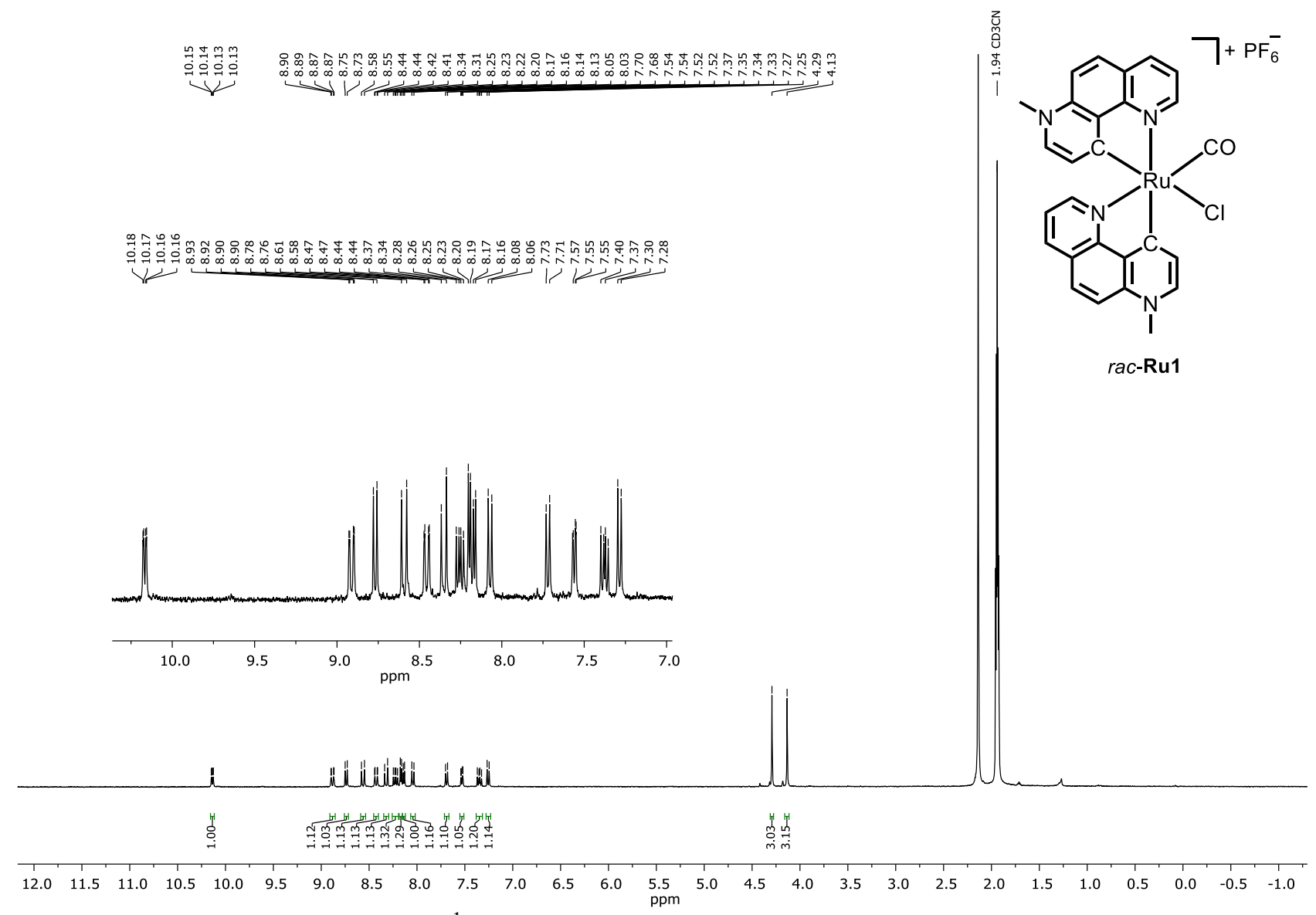

Figure S7. ${ }^{1} \mathrm{H}$ NMR $(300 \mathrm{MHz})$ of $\mathrm{rac}-\mathbf{R u} 1$ in $\mathrm{CD}_{3} \mathrm{CN}$. 


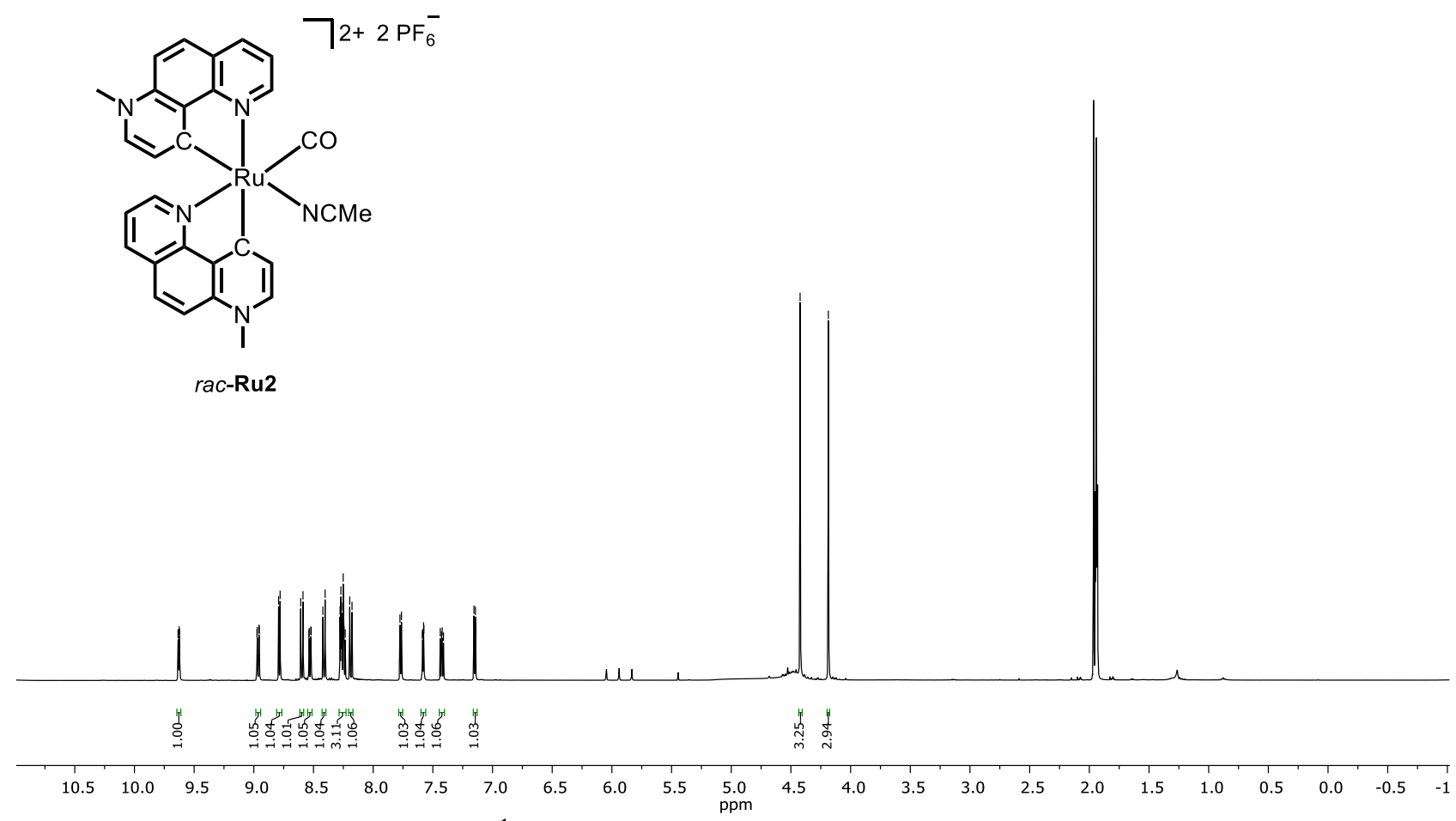

Figure S8. ${ }^{1} \mathrm{H}$ NMR (500 MHz) of rac-Ru2 in $\mathrm{CD}_{3} \mathrm{CN}$.

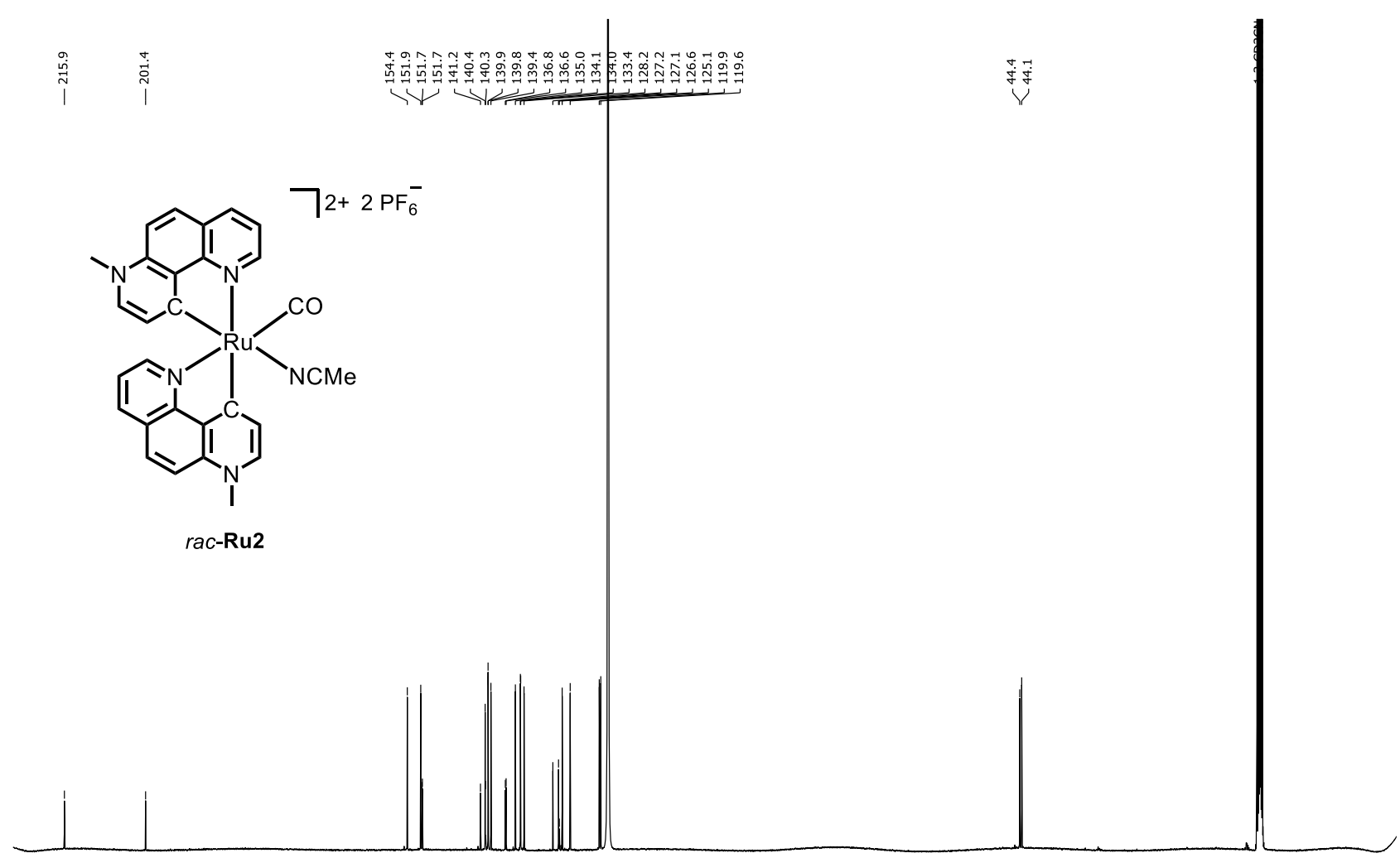

$\begin{array}{lllllllllllllllllllllllllllllllllll}220 & 210 & 200 & 190 & 180 & 170 & 160 & 150 & 140 & 130 & 120 & 110 & 100 & 90 & 80 & 70 & 60 & 50 & 40 & 30 & 20 & 10 & 0 & -10 & -20\end{array}$

Figure S9. ${ }^{13} \mathrm{C}$ NMR (126 MHz) of $r a c-R \mathbf{2} 2$ in $\mathrm{CD}_{3} \mathrm{CN}$. 


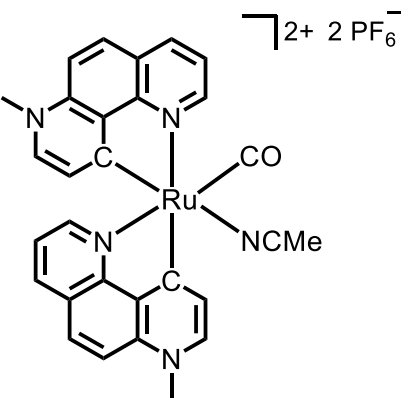

rac-Ru2

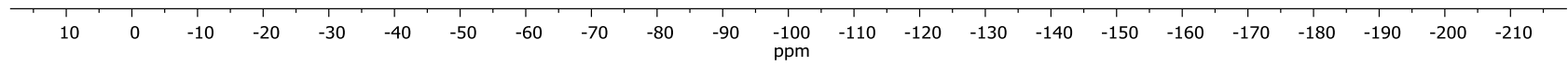

Figure S10. ${ }^{19} \mathrm{~F}$ NMR $(282 \mathrm{MHz})$ of $r a c-\mathbf{R u} 2$ in $\mathrm{CD}_{3} \mathrm{CN}$.

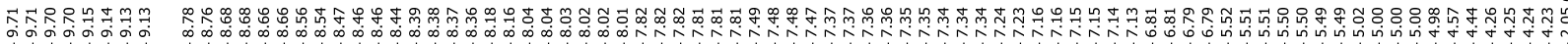

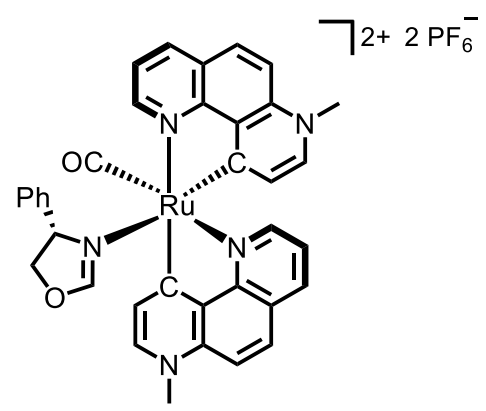

$\Delta-(S)-$ Ru3

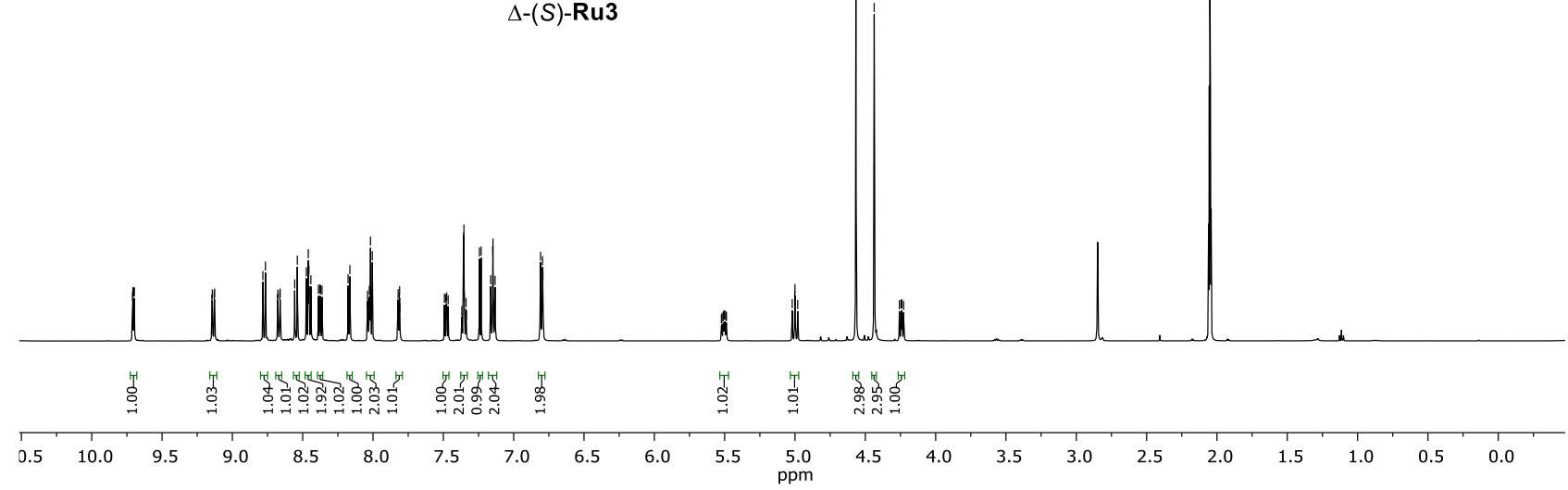

Figure S11. ${ }^{1} \mathrm{H}$ NMR $(500 \mathrm{MHz})$ of $\Delta$-(S)-Ru3 in acetone- $d_{6}$. 

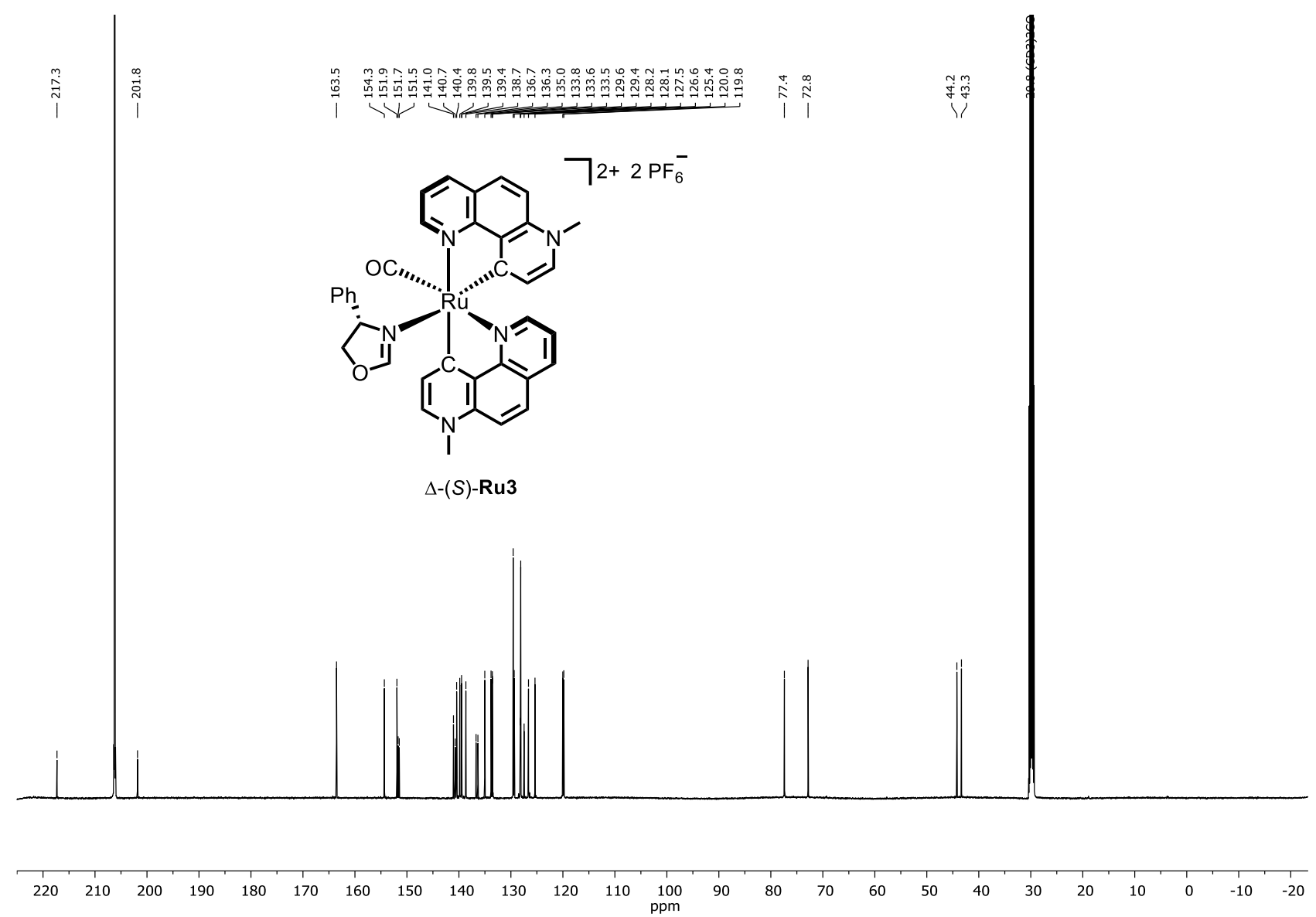

Figure S12. ${ }^{13} \mathrm{C}$ NMR $(126 \mathrm{MHz})$ of $\Delta-(S)-\mathbf{R u 3}$ in acetone- $d_{6}$.

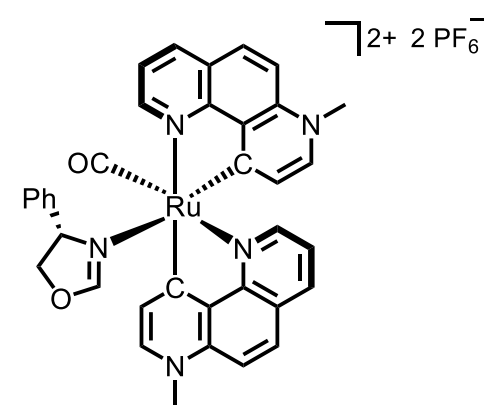

$\Delta$-(S)-Ru3

Figure S13. ${ }^{19} \mathrm{~F}$ NMR $(282 \mathrm{MHz})$ of $\Delta$ - $(S)-\mathbf{R u} 3$ in acetone- $d_{6}$. 
<smiles>O=c1onc(CCCc2ccccc2)o1</smiles>

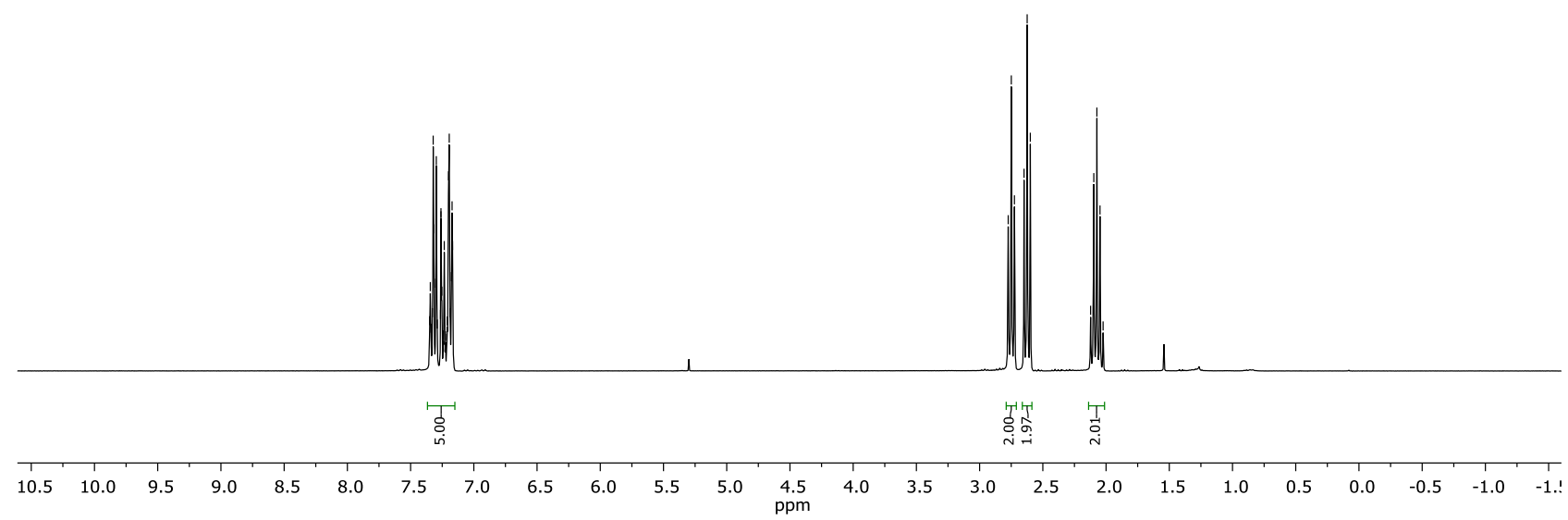

Figure S14. ${ }^{1} \mathrm{H} \mathrm{NMR}(300 \mathrm{MHz})$ of 3 in $\mathrm{CDCl}_{3}$.
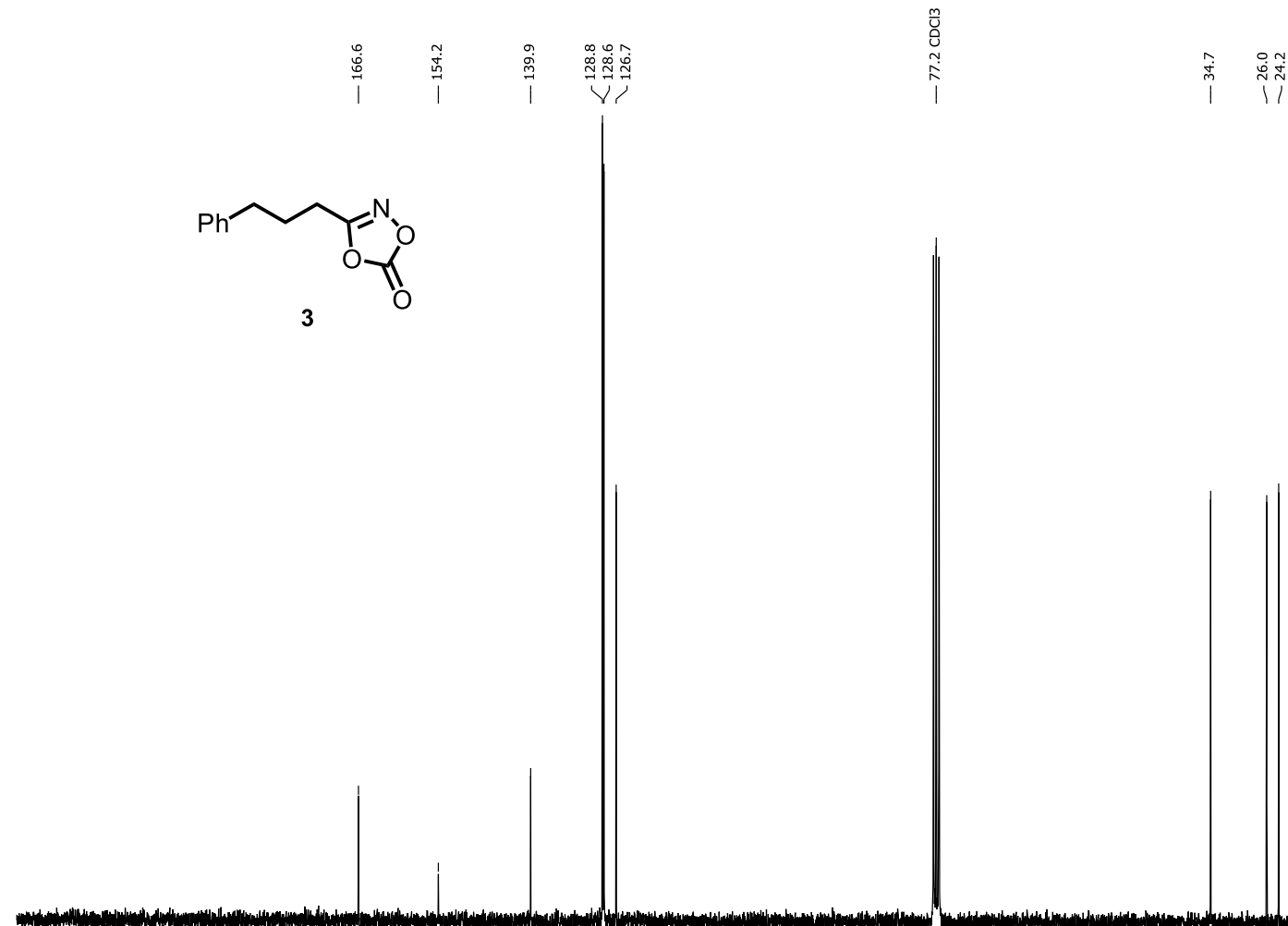

$\begin{array}{llllllllllll}210 & 200 & 190 & 180 & 170 & 160 & 150 & 140 & 130 & 120 & 110 & 100 \\ \mathrm{ppm}\end{array}$

Figure S15. ${ }^{13} \mathrm{C}$ NMR (75 MHz) of 3 in $\mathrm{CDCl}_{3}$. 


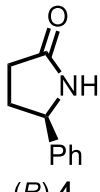

(R)-4

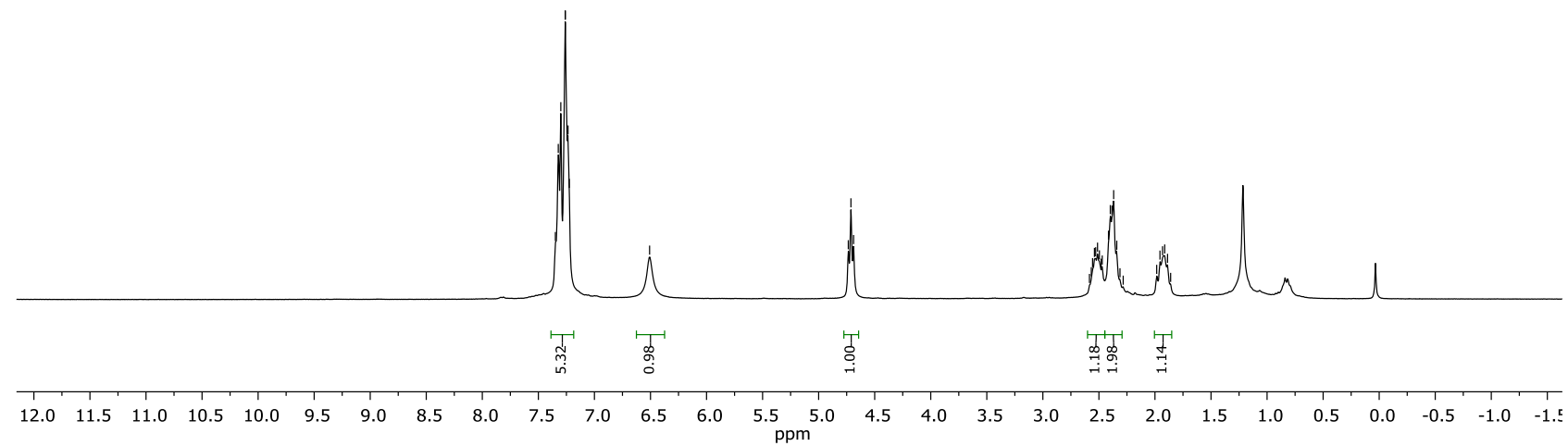

Figure S16. ${ }^{1} \mathrm{H}$ NMR $(300 \mathrm{MHz})$ of $(R)-4$ in $\mathrm{CDCl}_{3}$. 


\section{CD Spectra}

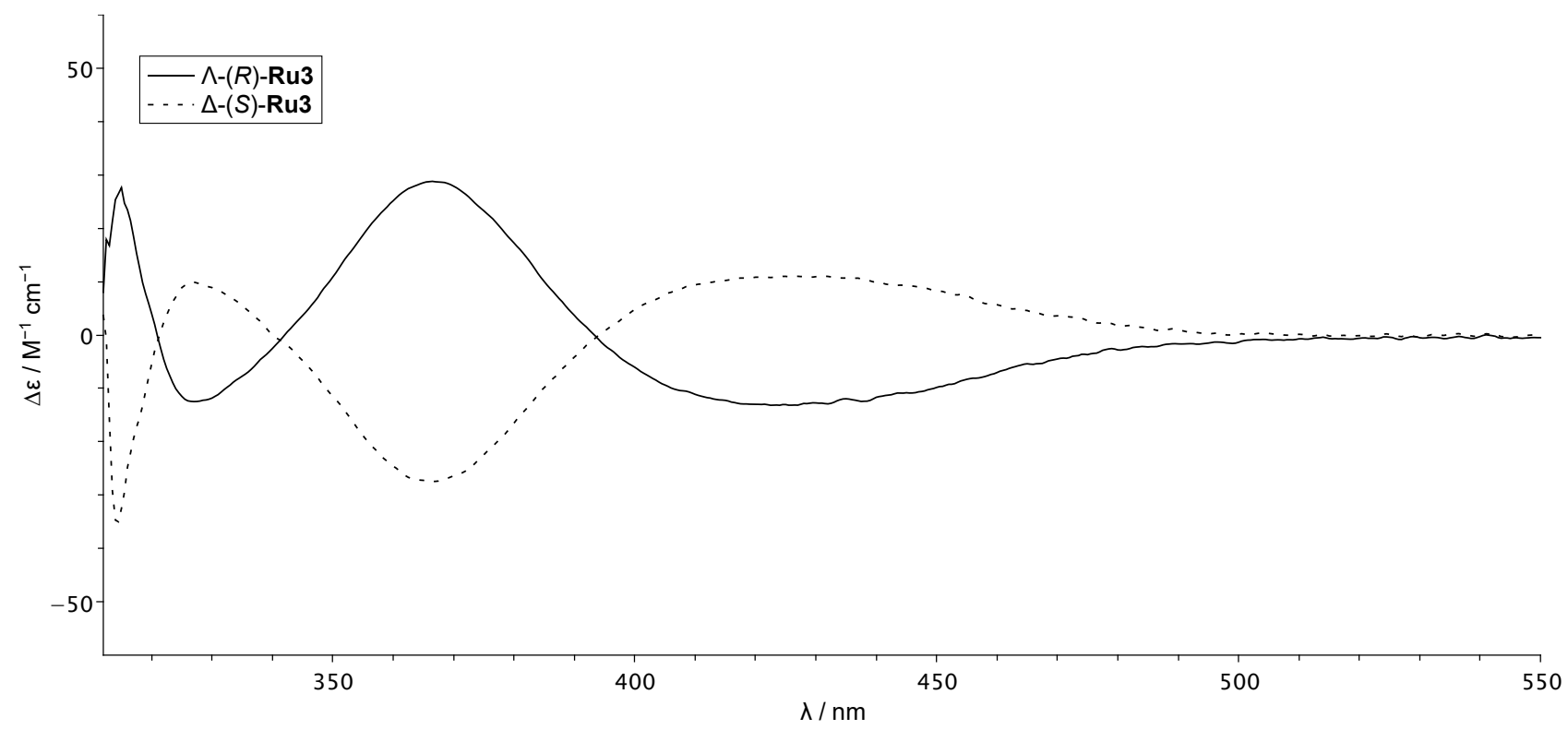

Figure S17. CD spectra of $\Lambda-(R)-\mathbf{R u 3}$ and $\Delta-(S)-\mathbf{R u 3}(0.25 \mathrm{mM}$ in acetone).

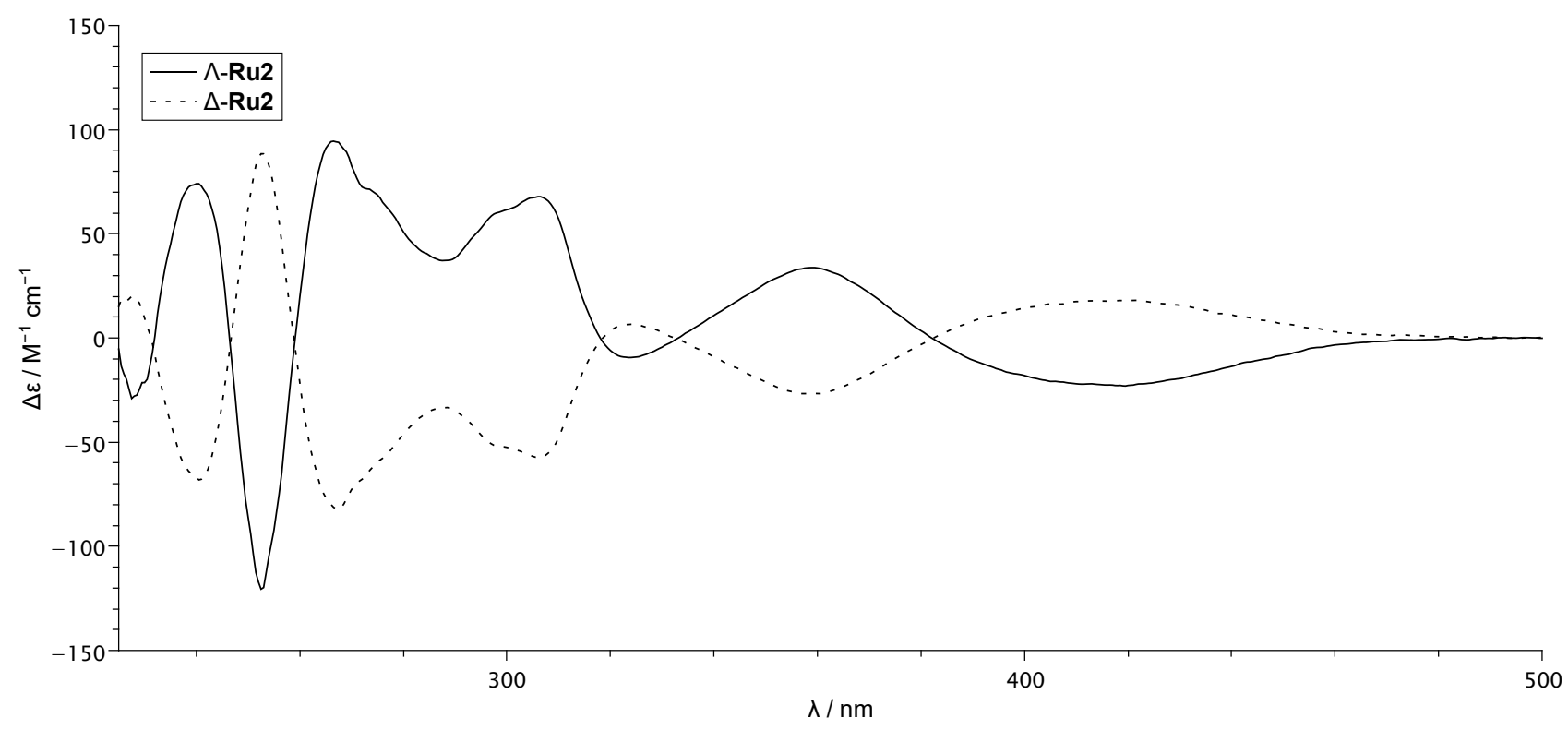

Figure S18. CD spectra of $\Lambda-\mathbf{R u} 2$ and $\Delta-\mathbf{R u} 2(0.25 \mathrm{mM}$ in $\mathrm{MeCN})$. 


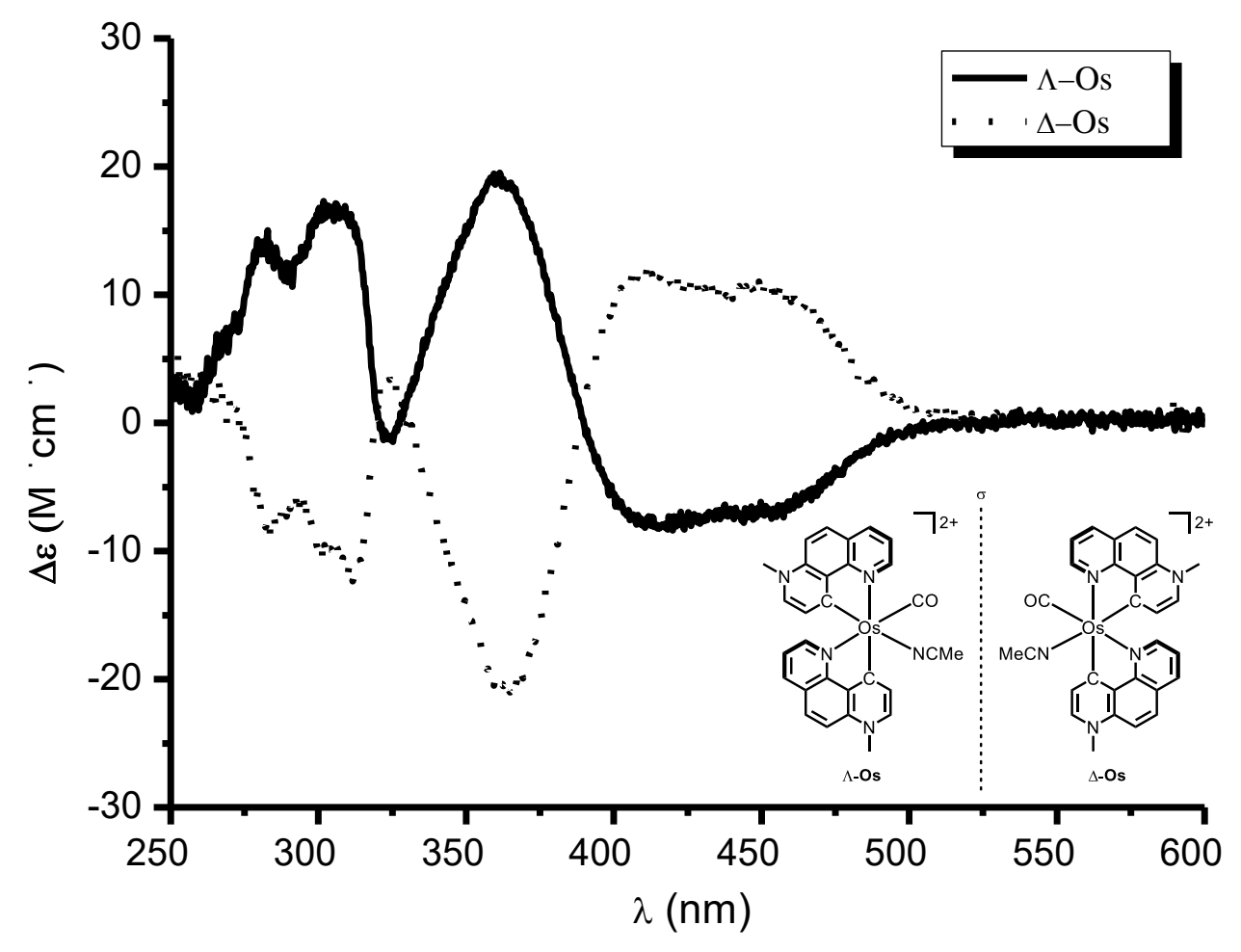

Figure S19. Compared CD spectra $(1.0 \mathrm{mM}$ in $\mathrm{MeCN})$ of the previously reported Os complex ${ }^{\mathrm{s} 9}$ for the determination of the metal centered stereoconfiguration.

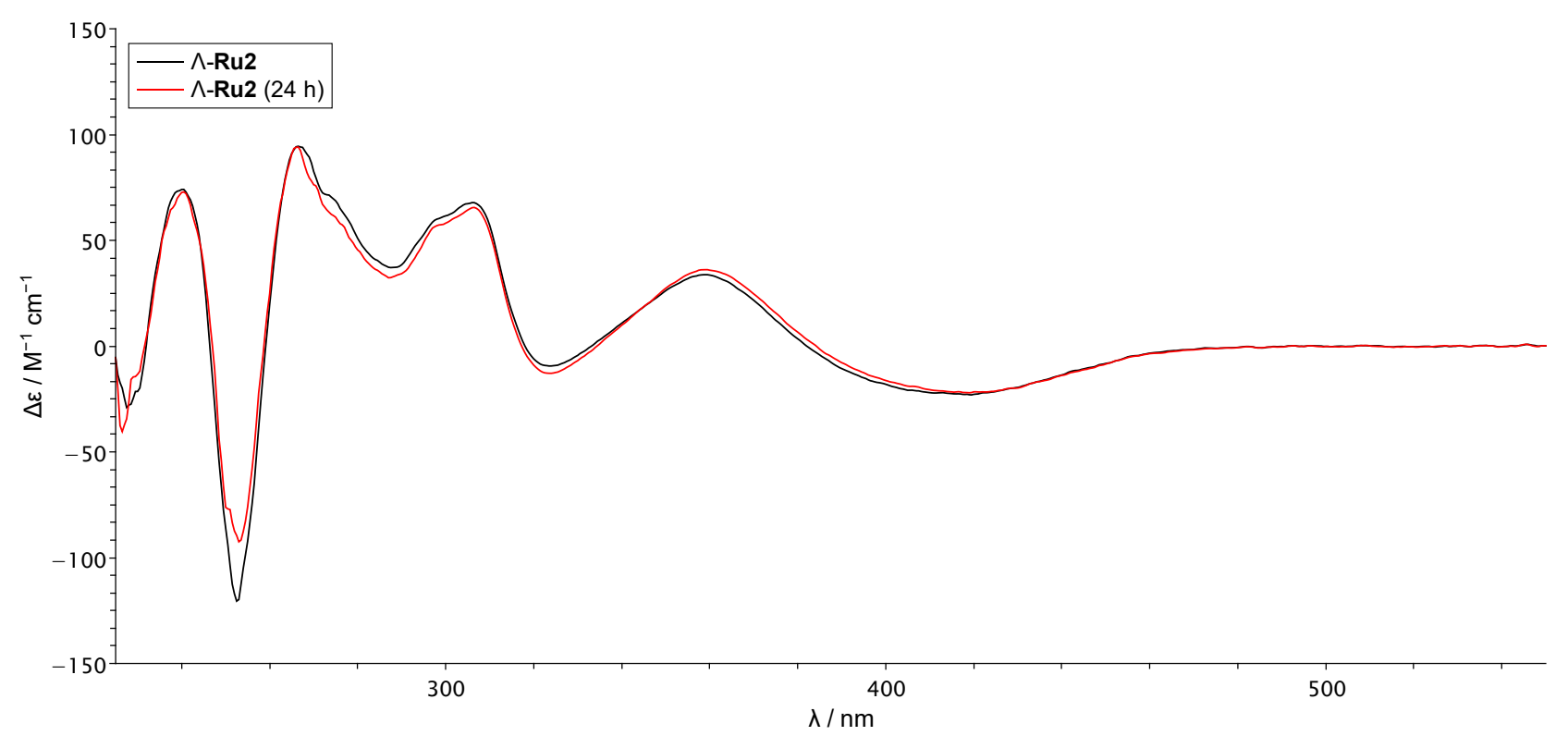

Figure S20. CD spectra of $\Lambda$-Ru2 after dissolution and after $24 \mathrm{~h}(0.25 \mathrm{mM}$ in $\mathrm{MeCN})$. 


\section{Chiral HPLC Traces}
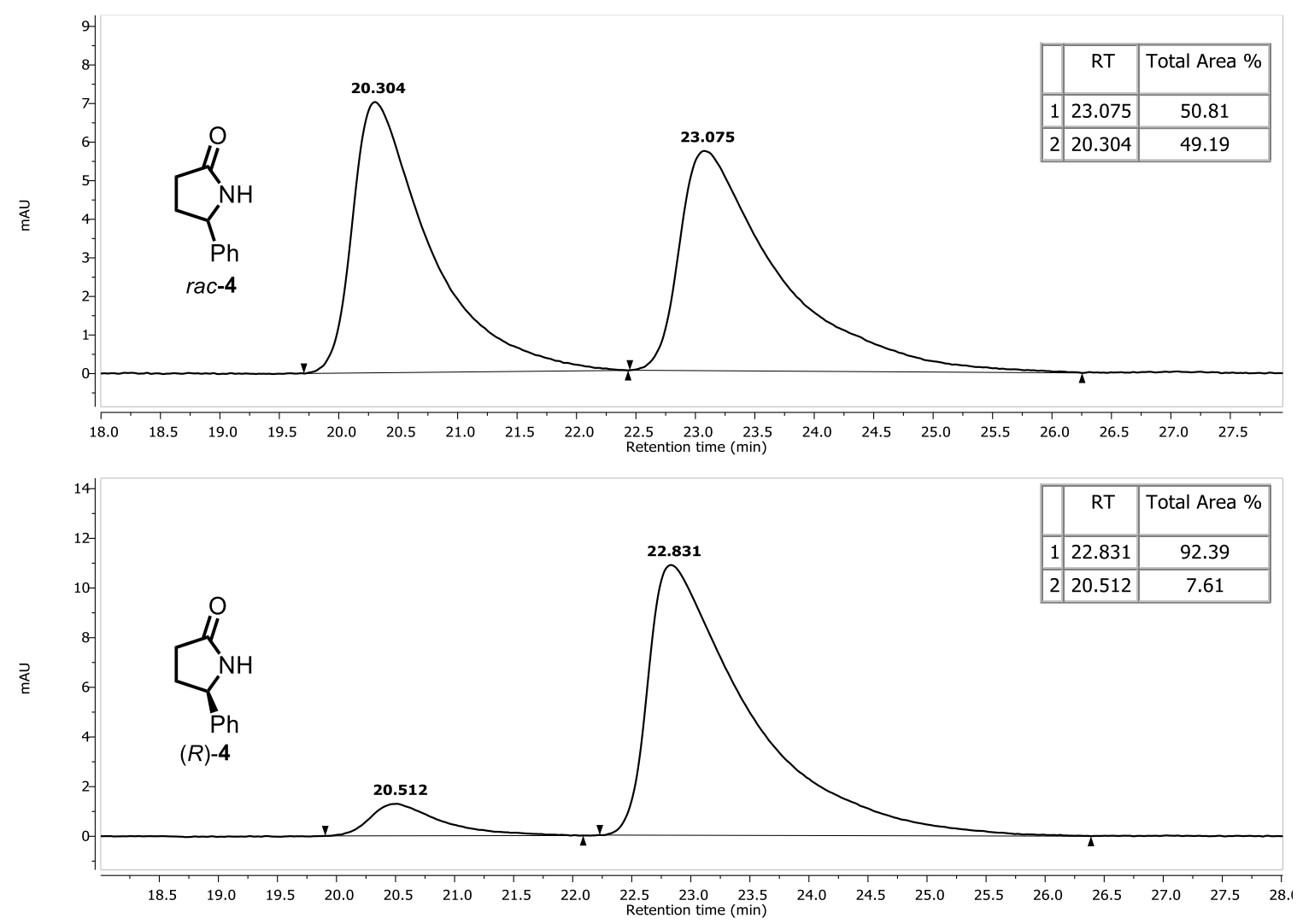

Figure S21. HPLC traces of rac-4 and (R)-4 (92:8 er). 


\section{References}

(s1) APEX3, Bruker AXS Inc., Madison, Wisconsin, USA, 2018.

(s2) SADABS, Bruker AXS Inc., Madison, Wisconsin, USA, 2016.

(s3) Krause, L.; Herbst-Irmer, R.; Sheldrick, G. M.; Stalke, D. Comparison of silver and molybdenum microfocus X-ray sources for single-crystal structure determination. J. Appl. Cryst. 2015, 48, 3-10.

(s4) Sheldrick, G. M. SHELXT - Integrated space-group and crystal-structure determination. Acta Cryst. A 2015, 71, 3-8.

(s5) Sheldrick, G. M. Crystal structure refinement with SHELXL. Acta. Cryst. C 2015, 71, 3-8.

(s6) Hübschle. C. B.; Sheldrick, G. M.; Dittrich, B. ShelXle: a Qt graphical user interface for SHELXL. J. Appl. Cryst. 2011, 44, 1281-1284.

(s7) Spek, A. L. PLATON SQUEEZE: a tool for the calculations of the disordered solvent contribution to the calculated structure factors. Acta Cryst. $C$ 2015, 71, 9-18.

(s8) Spek, A. L. PLATON - A Multipurpose Crystallographic Tool; Utrecht University, Utrecht, The Netherlands, 2019.

(s9) Wang, G.; Zhou, Z.; Shen, X.; Ivlev, S.; Meggers, E. Asymmetric catalysis with chiral-atosmium complex. Chem. Commun. 2020, 56, 7714-7717. 